\title{
ADAPTIVE TECHNOLOGIES FOR THE BLIND AND VISUAL IMPAIRED PERSONS IN THE TRAFFIC NETWORK
}

\author{
Marko Periša ${ }^{1}$, Dragan Peraković ${ }^{2}$, Juraj Vaculík ${ }^{3}$ \\ ${ }^{1,2}$ Dept of Information and Communications Traffic, University of Zagreb, Croatia \\ ${ }^{3}$ Dept of Communications, University of Žilina, Slovakia
}

Submitted 26 August 2014; resubmitted 20 October 2014; accepted 19 December 2014; first published online 28 January 2015

\begin{abstract}
The information about the environment and the precise guidance of visually impaired people is the basis for their safe movement of the traffic network. Therefore, the information and communication services should be adapted to this group of users. The services based on the advanced information and communication technologies provide the visually impaired persons with information about the environment while moving along the traffic network. This paper analyses the currently available information systems of users when moving traffic network, and the currently most services based on new ICT (Information and Communications Technology). The analysis was carried on a representative sample of the City of Zagreb (Croatia) in involving all interest groups of visually impaired people. Based on defined user requirements is proposed a new services based on NFC (Near Field Communication) and RTLS (Real-Time Locating Systems). Testing and analysing the efficiency of single information and communication technologies have been performed on the actual traffic network system of the City of Zagreb. The users of the Croatian Society for Promotion and Development of Tiphlotechnology (Hrvatska Udruga za Promicanje i Razvoj Tiflotehnike - HUPRT, http://www. huprt.hr) participated in checking the efficiency of single technologies and services.
\end{abstract}

Keywords: real-time locating systems; traffic network; assistive technology; information system; communication.

\section{Introduction}

In the Republic of Croatia there are currently 17979 persons with poor eyesight, whereas in the capital, Zagreb, there are 1,985 persons with impaired vision (Benjak 2013). The City of Zagreb covers an area of $641.35 \mathrm{~km}^{2}$ which is $1.13 \%$ of the Croatian territory. The position of the City of Zagreb in regional - Central European space marks an interrelation of three biggest cities that connect history, present and past - the triangle Zagreb-Vienna-Budapest; a lower level is the connection ZagrebGraz-Trieste with Ljubljana in the centre, and in Croatia this is the triangle Rijeka-Split-Osijek with Zagreb in the centre. In the City of Zagreb the traffic intersections are equipped with audio and tactile information. This research presents the evaluation of the quality of the information done by the blind and visually impaired persons (the Target Group of Users - TGU) when moving through the urban traffic network.

The aim of this paper is to define adequate wireless technology for the recognition and information of the users according to user requests. Today's development of information and communication technologies and services in this area can contribute to the improvement of the quality of living of TGUs when moving along the traffic network. Apart from the standard audio signal which is used for navigation through the traffic intersection also the development of new solutions and services based on RFID (Radio-Frequency IDentification) technologies is possible, which is shown in many scientific studies from this area (Willis, Helal 2005; Nassih et al. 2012; Crespo et al. 2012).

In these studies RTLS (Real-Time Locating Systems) and RFID technology was used in the function of getting exact information about location of the user. Visually impaired people currently used for navigation applications who is exclusively based on GPS (Global Positioning System) technology (Hersh, Johnson 2008; Keefer et al. 2013; Au et al. 2013). The main problem in determining the location using GPS is getting a correct information about location and the environment. Informing them of users who is located in the traffic intersection zone is possible using NFC (Near Field Communication) and GSM (Groupe Spécial Mobile Global System for Mobile Communications) technology (Peraković et al. 2013). 


\section{Analysis of Technology in the Function of Identification and Information User's}

This paper analyse the currently available technologies (RFID, Wi-Fi, NFC and Bluetooth), to identify and informing users. The technologies have been analysed with the aim of obtaining the precise position of the user who uses it (Fig. 1).

Important characteristic of specific technologies is the capacity of data, which is important in terms of informing the user. With RFID technology specified data depends on the set, passive tag data have a capacity of 48 bytes to 736 bytes. The active tag has a capacity of 64 bytes to $32 \mathrm{~KB}$, and read-only, have a capacity of $20 \mathrm{bit}$ (Yang et al. 2013). RFID technology with these specifications is used in the identification of traffic and transport entities. During what is important to define the requirements which are necessary for the determination of RFID tags (Andziulis et al. 2012). In these works was analysed RFID sensor technology, readers and tags, and the result of this is indicate that the integration of risk management practice into transportation processes via a mobile control system increases intermodal container transportation mobility, safety and overall effectiveness.

The Bluetooth technology depends on which version that the mobile terminal device has, it is only used to transmit information to the user. Transmission speed depends on the version, the latest version of the Bluetooth SIG (V 4.0LE) allows speeds of $25 \mathrm{Mbps}$. The NFC technology allows data transfer rate up to $424 \mathrm{kbit} / \mathrm{s}$, along with RFID technology is the point-to-point communication, and the extent of less than $0.2 \mathrm{~m}$.

The wireless technology enables transfer speeds depending on the protocols, standard protocols working at frequencies of $2.4 \mathrm{GHz}(802.11 \mathrm{~b}$ and $802.11 \mathrm{~g})$ and $5 \mathrm{GHz}$ (802.11a) and provide transmission speeds up to $54 \mathrm{Mbit} / \mathrm{s}$.

The mobile terminal devices which are adapted for the visually impaired are equipped with these technologies. The basic functionalities independently used $84 \%$ of surveyed users, while $16 \%$ of users have a problem due to lack of adaptation. This data is important because they analysed the most common mobile terminal devices, which are equipped with these technologies (Bluetooth, Wireless and NFC).

For more precision in obtaining information about the location of the user moving along the traffic network, it is recommended to use RFID technology. This technology is used to identify the user and to inform the traffic intersection management system. The user's gets information using mobile terminal devices. Mobile terminal device uses $99 \%$ of the users who participated in the survey, which is represents the based in designing of new solutions and services. The possibilities of informing users using mobile applications is require access to RFID, NFC, Wi-Fi/RTLS and Bluetooth technologies. These technologies enable access to all relevant information - intersection, traffic, real-time, guidance and POI (Points Of Interest) - as shown in Fig. 2.

\section{Model of Information Blind and Visually Impaired Persons}

The system of informing the User about the environment, and further guidance is important from the aspect of feeling safety. The survey was planned to be applied on a sample of 175 users, who move and live in the City of Zagreb. The survey has involved 144 users, which is $82 \%$ of the total figure. Representative sample has been defined according to the Croatian Blind Union and the Zagreb Association of the Blind Persons of according to the number, which is 171 , of Blind and Visually Impaired (significant amblyopia) people employed in the City of Zagreb. The poll has involved 101 users who are employed, which make $59 \%$ of the total number of employees, so this sample is considered to be representative. This sample has been selected because these customers are moving around the City of Zagreb daily. The users who move every day use as the aid exclusively the white stick and have no assistant. This movement of the

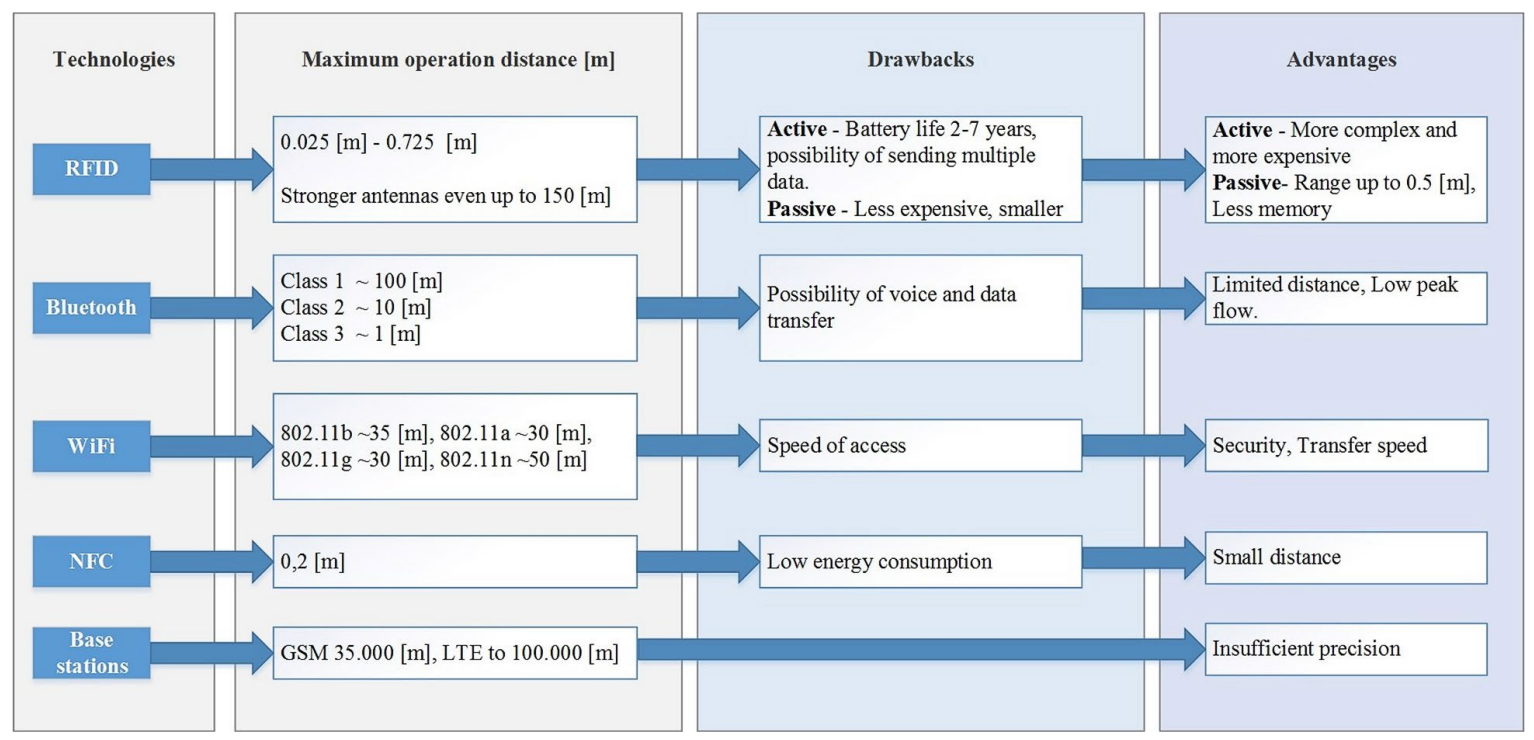

Fig. 1. Characteristics of other technologies in positioning of the user (Peraković et al. 2013) 


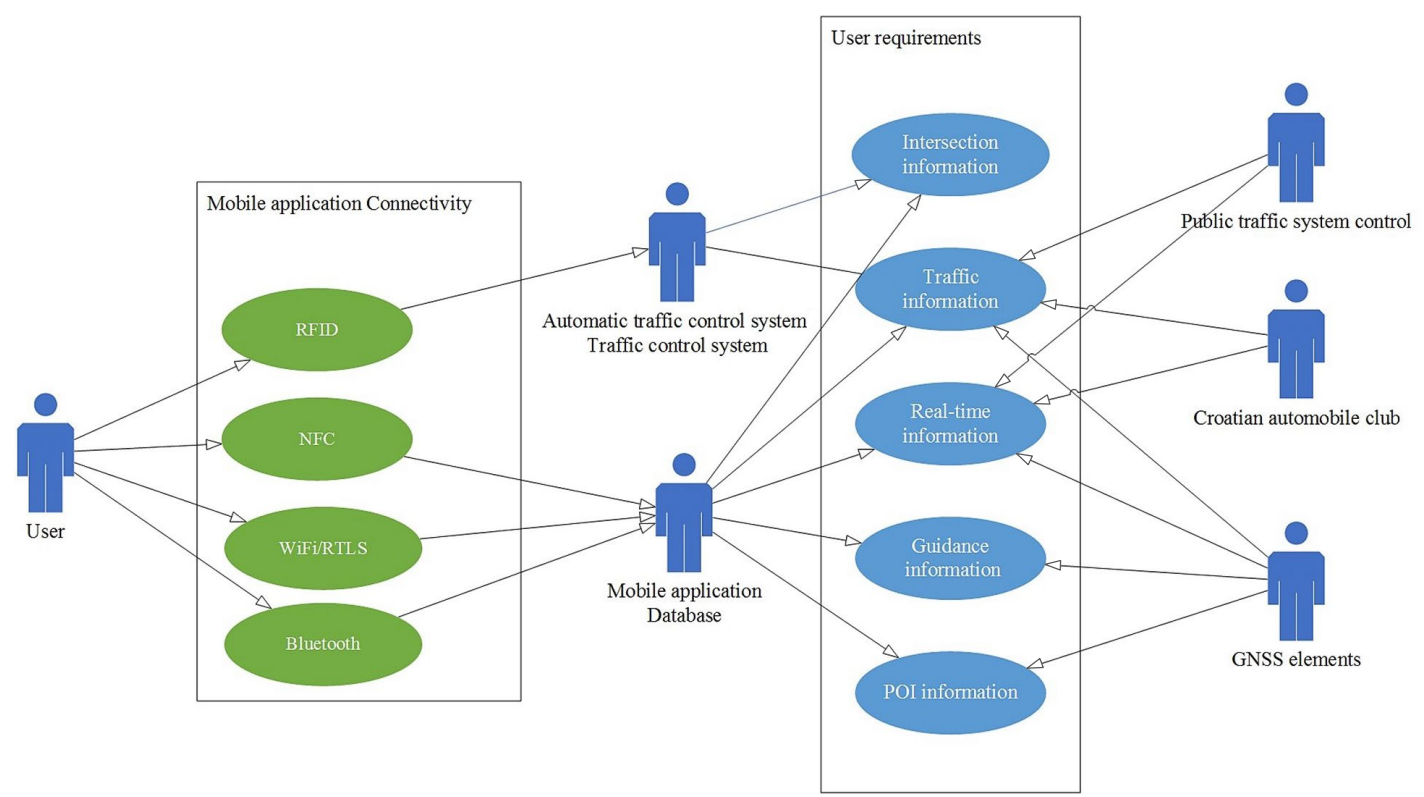

Fig. 2. The preview of fulfilling of user requirements based on different mobile application connectivity

users is important because this research does not define the guidelines for the development of a new aid, but enables improvement of the current system of managing a signal-controlled intersection with new technologies. The City of Zagreb has been defined as the research location because of the biggest number of users who move independently along the traffic network. The analysis of the current movement method of the users has been carried out at the most used routes. In the survey, the users selected the route and the traffic intersection at which their level of safety is the lowest. The traffic intersection at which the study was carried out, was equipped only by audio signals and the pedestrian crossings are set at an angle of 30 degrees. The information that were found on audio signalling devices did not contain all the necessary information for safe managing of the crossings, and for user information. The current operation of the signal-controlling system does not provide dynamic change of the operation mode, but is rather based exclusively on the pre-defined algorithm. The currently users information system at the traffic intersections is audible and tactile information. Evaluation accuracy of customer satisfaction on currently informing at traffic intersection in the City of Zagreb is presented in Fig. 3.

Model of information users is based on the usage of navigation application adapted to the visually impaired persons, the mobile terminal device and identification system. Because of errors that occur when using the navigation applications (GPS as method for independent guidance and navigation), another technology (RTLS, RFID, Bluetooth or NFC) is added to this working method. For using this method of work the user must have a white cane, mobile terminal device (external or integrated GPS receiver), application which enables guidance and navigation of users and RTLS tag. The user's movement is divided into three zones of identification presented in Fig. 4 (El Alamy et al. 2012; Periša 2013). a)

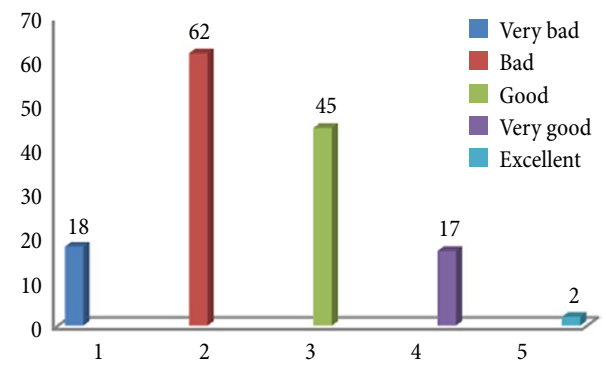

b)

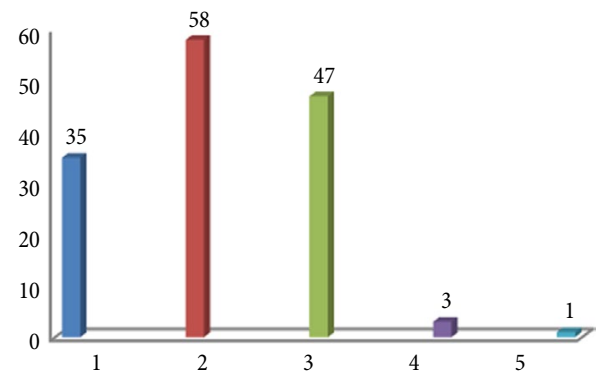

Fig. 3. User satisfaction with: a - audio information; $\mathrm{b}$ - tactile information

The first zone is defined in the radius of $1 \mathrm{~m}$ in relation to the audio indicator, which at the same time defines also the initial point of crossing. The second zone is defined at the distance of $10 \mathrm{~m}$ in the direction of the user's arrival, and the third zone at a distance of $30 \mathrm{~m}$. The mentioned zones are defined through the carried out research of the analysis of applications for the guidance and navigation and the conditions of traffic intersections in the City of Zagreb. For the size of the third zone, the distance is considered as sufficient for the orientation of the user in relation to the audio signal, which would be activated after having identified the user. The identification zones allow the obtaining of precise information received by the user about the distance that is required to arrive to the first point of crossing the traffic intersec- 


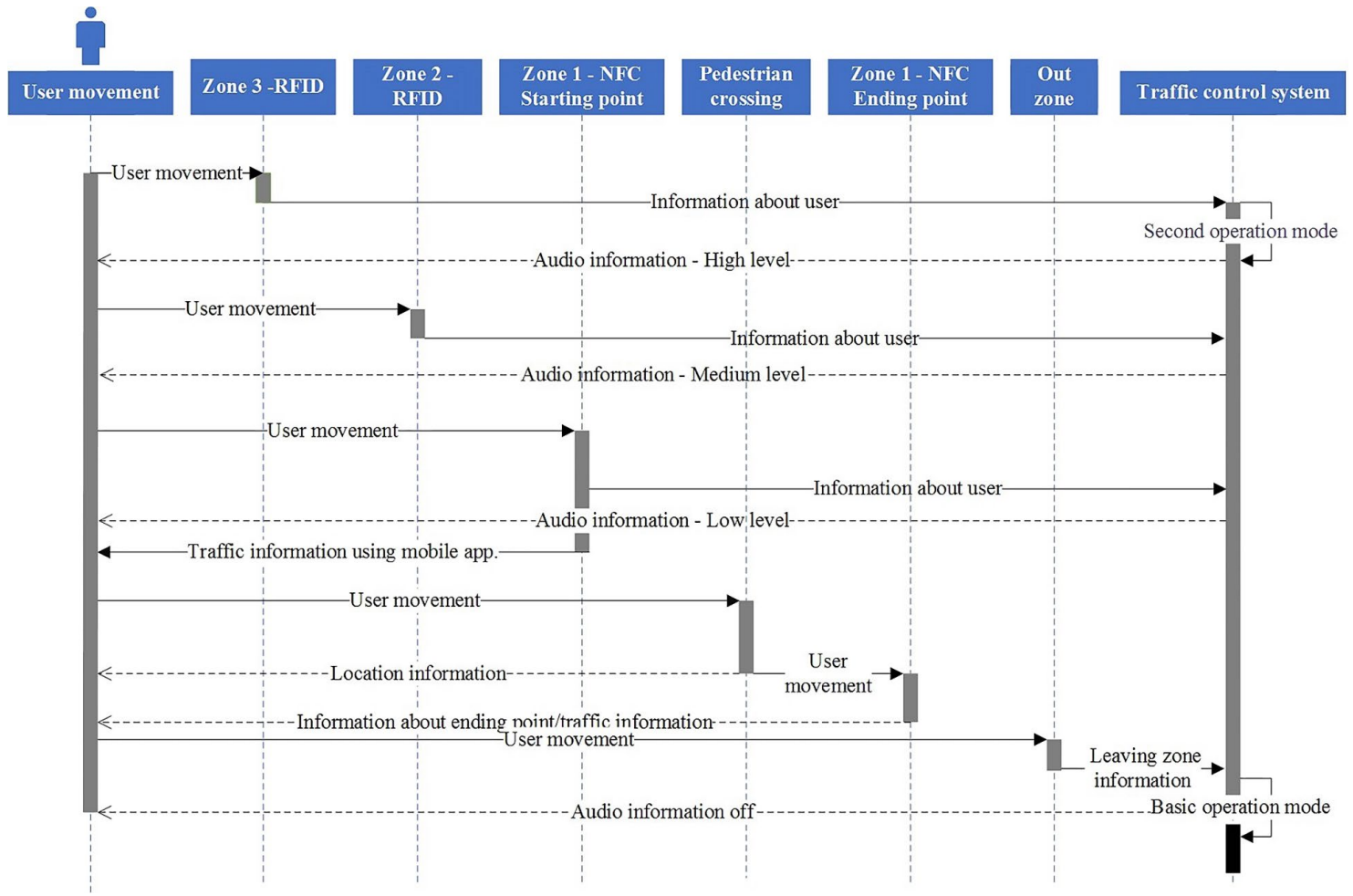

Fig. 4. Zones of identification and navigation of users

tion. The user moves along the traffic network receiving along the way via mobile device the information on their movement which is based on GPS navigation and application used by the user and the pre-defined route of moving. Sound indicators are input as POI according to which the user is navigated. The POI inherently also use the information about the traffic intersection.

When the user enters the third identification zone, the system controlling the traffic lights receives the information and changes the operation mode. For the identification, the user must have an RTLS tag, which is identified by an antenna directed towards their moving. The traffic light system receives information from the RTLS controller, which, after having received the information prolongs the green phase for pedestrians, allows activation of the audio signal and provides information for the user at arrival to the initial point of crossing. The average speed has been obtained by measuring during the analysis of the traffic intersection, and the mean value of ten performed measurements has been taken $\left(v_{k}=0.55 \mathrm{~m} / \mathrm{s}\right)$ (Periša et al. 2014).

Upon arrival to the initial point of crossing the intersection (audio button 1), the user receives information on their location and all the necessary information about the traffic intersection. The information that the user can receive includes:

- size of the intersection (how many lanes in which direction);

- street names (defined according to the geographical directions);

- existence of landmarks;

- tactile elements of accessibility;
- tramway lines;

- possible directions of movement.

If the pedestrian crossing is at an angle (example the intersection of Zvonimirova and Šubićeva Streets), the user also obtains this information and aligns the body to the respective position. For instance: Direction of movement North-South, Šubićeva Street, position of body $30^{\circ}$ to the right.

The user receives the information via mobile device if the point of interest has been input with a commentary or by using the technology such as Bluetooth and NFC, which serves to read the information from the indicator. After confirmation of the traffic light system for crossing the road, the user passes along the pedestrian lane and arrives to the destination point (audio button 2). Upon arrival, the user receives information that they have arrived at the destination, and the information about the possibility of further moving by using the directions of movement according to the geographical directions.

The exit of the user from the system is identified by RTLS that forwards the information to the traffic-light system, which returns to the initial mode of operation. The time interval is determined according to the size of the traffic intersection and the traffic volume that runs through it. After exiting the system the user receives the information on the mobile device that they have exited the traffic intersection zone. The user can move toward the destination point by using the application for guidance or navigation (point of interest 2) or by the emitted audio signal. The user's passing is presented in Fig. 5, which shows the method of user's movement and possible information that surround them. 


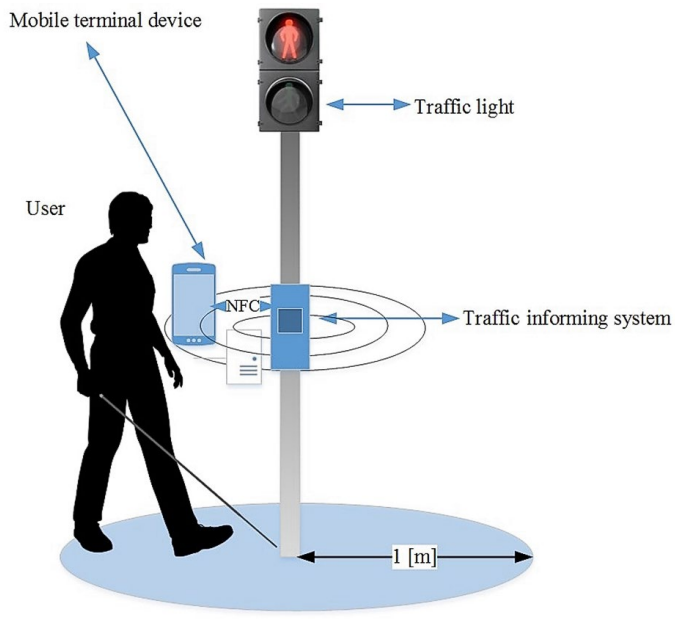

Fig. 5. Informing users using NFC technology and mobile terminal device

\section{RTLS Architecture for User Information and Identification}

Information and communication system of identification and user service provision is based on RTLS technology. The components of the system include:

- reader with Wi-Fi antenna and controller;

- transponder (card or tag);

- the central computer.

Fig. 6 shows the architecture of the system when the user is moving along the traffic network. The RTLS being used exclusively in closed spaces, where external GPS errors are large. GPS errors for visually impaired person can endanger lives when moving Traffic network. The above technology is compatible with the analysed technologies such as RFID, WLAN, Wi-Fi and NFC. The UML (Unified Modelling Language) diagram activity is presented system performance when users in the first zone RTLS identifies user and informs him with sound information that is at the starting point of crossing the intersection. Using a mobile terminal device and the available technology (NFC, Bluetooth and Wi-Fi) user gets all the necessary information about the future movement and environment.
The information and identification system has to provide the basic user's requirements in order to adjust the system to the visually impaired persons, as well as to other users in traffic. The user's requirements define the basic information the system has to provide to the user (Periša 2013):

- information on location;

- information on guidance and navigation;

- information on objects surrounding the user;

- information of audio character;

- information of descending and ascending kerb;

- information on traffic intersection;

- information on the method of traffic control (tactile lines, traffic light system or something else);

- information of the right moment to cross the street;

- information on system operation (system breakdown or upgrade);

- information on arrival to the destination.

Information of the user at the initial point of crossing is done by using the mobile terminal device, Bluetooth headset or by means of device speakers and NFC reader. Mobile terminal device can have the role of a reader, transponder, which communicates with the terminals and peer-to-peer data exchange.

\section{Conclusions}

Management of traffic light system during movement of blind and visually impaired transport network allows the use of RTLS to identify and NFC system for informing the user. The results of checking the efficiency of the mentioned models have enabled safe and independent movement along the traffic intersection. The user had all the relevant information about the environment and about the configuration of the traffic intersection, thus improving the user's perception. Apart from raising the level (perception) of safety by the users, the proposed mode of operation is expected also to increase the level of mobility and information. Higher mobility of users allows the users to move according to their requirements, and not according to the frequently used routes.

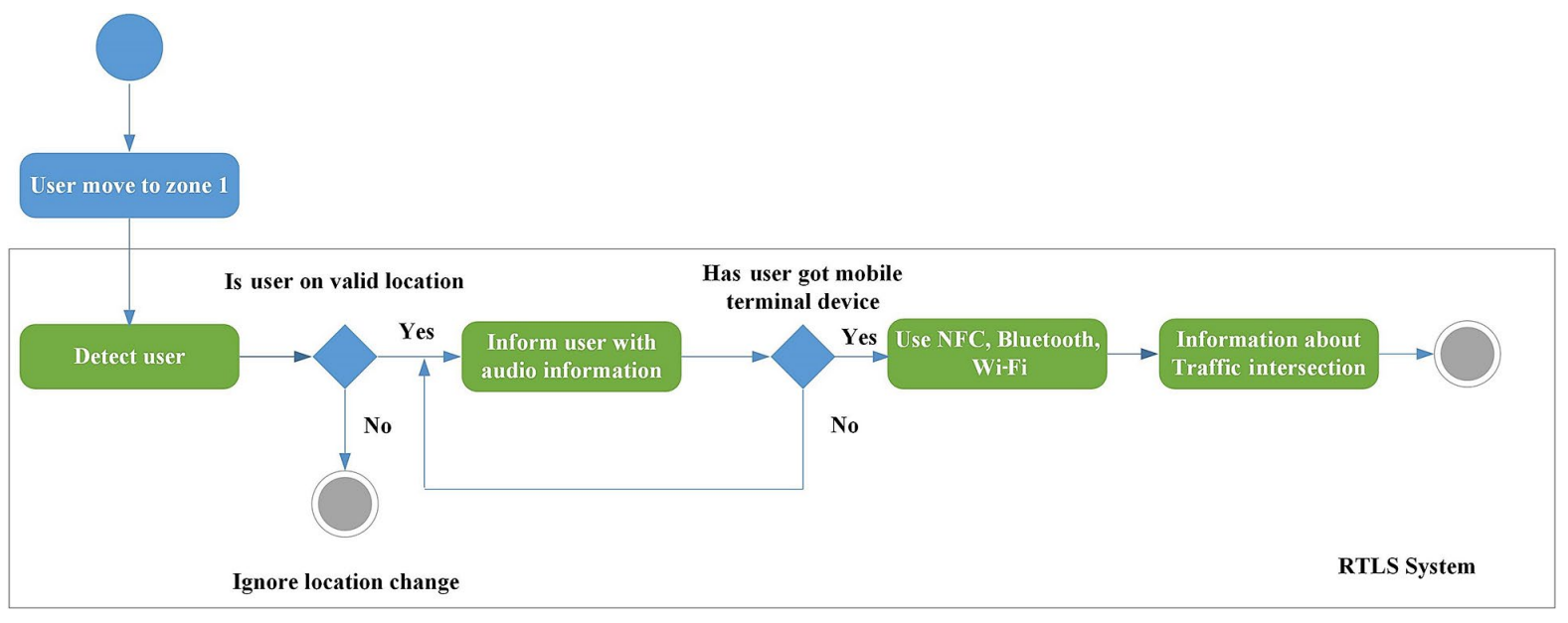

Fig. 6. System architecture for information and identification users 
The user speed is the parameter, which affects the mode of traffic light operation for pedestrians (users) since it is in direct relation to the green phase duration. The change in the operation mode would allow longer duration of the green phase and at the same time also audio information sufficient for safe crossing and arrival to the destination. The current operation method confuses the users and additionally endangers their safety.

The analysed technologies meet through their technical characteristics all the needs for identifying and navigating the users to the starting point of the crossing and the destination. The mentioned technologies have also been recommended to inform the users about their surroundings thus additionally raising the level of user safety.

More efficient usage of the currently available technology and its functionality would make it possible for the blind and visually impaired persons to enhance the quality of their lives. The users' requirements have enabled the adjustment to the user according to the requested information without endangering other traffic factors. The application of new information and communication technologies and better utilization of the functionality of mobile terminal devices enable increasing the quality of life visually impaired persons. For this purpose, it is necessary that the mobile terminal devices and applications are available to all groups of visually impaired persons.

\section{Acknowledgements}

This research has been carried out as part of the project 'Information and Communication Services for the Movement of Persons with Reduced Mobility along the Traffic Network'.

The project is registered under number 5415 and funded as part of the program 'Short-term Financial Support of Research', University of Zagreb (Croatia), 2013.

\section{References}

Andziulis, A.; Plěštys, R.; Jakovlev, S.; Adomaitis, D.; Gerasimov, K.; Kurmis, M.; Pareigis, V. 2012. Priority based tag authentication and routing algorithm for intermodal containers RFID sensor network, Transport 27(4): 373-382. http://dx.doi.org/10.3846/16484142.2012.750622

$\mathrm{Au}$, A. W. S.; Chen, F.; Valaee, S.; Reyes, S.; Sorour, S.; Markowitz, S. N.; Gold, D.; Gordon, K.; Eizenman, M. 2013. Indoor tracking and navigation using received signal strength and compressive sensing on a mobile device, IEEE Transactions on Mobile Computing 12(10): 2050-2062. http://dx.doi.org/10.1109/TMC.2012.175

Benjak, T. 2013. Izvješće o osobama s invaliditetom u Republici Hrvatskoj. Hrvatski zavod za j avno zdravstvo, Služba za javno zdravstvo, Zagreb. 69 p. Available from Internet: http:// hzjz.hr/wp-content/uploads/2013/11/Bilten_invalidi_2012. pdf (in Croatian).

Crespo, G.; Teniente, J.; Ederra, I.; Gonzalo, R. 2012. Experimental study of the antenna influence in RTLS based-on RFID, in Proceedings of the 6th European Conference on Antennas and Propagation 2012, 26-30 March 2012, Prague, Czech Republic, 2500-2504.

http://dx.doi.org/10.1109/EuCAP.2012.6206172
El Alamy, L.; Lhaddad, S.; Maalal, S.; Taybi, Y.; Salih-Alj, Y. 2012. Bus identification system for visually impaired person, in Proceedings of the Sixth International Conference on Next Generation Mobile Applications, Services and Technologies, NGMAST 2012, 12-14 September, Paris, France, 13-17. http://dx.doi.org/10.1109/NGMAST.2012.22

Hersh, M. A.; Johnson, M. A. 2008. Assistive Technology for Visually Impaired and Blind People. Springer. $725 \mathrm{p}$. http://dx.doi.org/10.1007/978-1-84628-867-8

Keefer, R.; Liu, Y.; Bourbakis, N. 2013. The development and evaluation of an eyes-free interaction model for mobile reading devices, IEEE Transactions on Human-Machine Systems 43(1): 76-91. http://dx.doi.org/10.1109/TSMCA.2012.2210413

Nassih, M.; Cherradi, I.; Maghous, Y.; Ouriaghli, B.; SalihAlj, Y. 2012. Obstacles recognition system for the blind people using RFID, in Proceedings of the Sixth International Conference on Next Generation Mobile Applications, Services and Technologies, NGMAST 2012, 12-14 September, Paris, France, 60-63. http://dx.doi.org/10.1109/NGMAST.2012.28

Peraković, D.; Periša, M.; Runjić, T. 2013. System of identification and information of blind and visually impaired persons in the traffic network, in 5 ročník vedeckej konferencie Deň nových technológií [Day of New Technologies DONT], 25-30 October 2013, Žilina, Slovakia, 126-134.

Periša, M. 2013. Dinamičko vođenje $i$ usmjeravanje slijepih $i$ slabovidnih osoba u prometu [Dynamic Guiding and Routing of Disabled and Visually Impaired Persons in Traffic]: Doctoral Thesis. University of Zagreb, Croatia. 205 p. (in Croatian).

Periša, M.; Peraković, D.; Šarić, S. 2014. Conceptual model of providing traffic navigation services to visually impaired persons, Promet - Traffic\& Transportation 26(3): 209-218. http://dx.doi.org/10.7307/ptt.v26i3.1492

Willis, S.; Helal, S. 2005. RFID information grid for blind navigation and wayfinding, in Proceedings of the Ninth IEEE International Symposium on Wearable Computers 2005, 18-21 October 2005, Osaka, Japan, 34-37. http://dx.doi.org/10.1109/ISWC.2005.46

Yang, P.; Wu, W.; Moniri, M.; Chibelushi, C. C. 2013. Efficient object localization using sparsely distributed passive RFID tags, IEEE Transactions on Industrial Electronics 60(12): 5914-5924. http://dx.doi.org/10.1109/TIE.2012.2230596 